
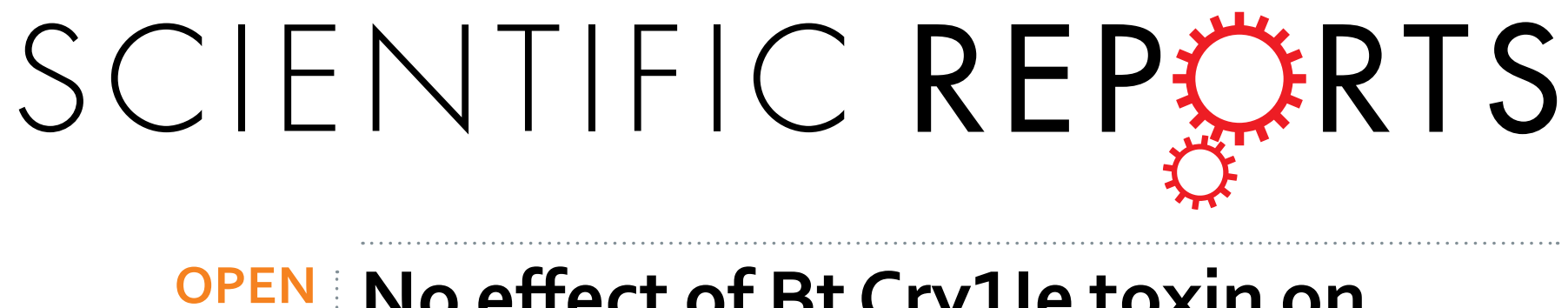

\title{
No effect of Bt Cry1le toxin on bacterial diversity in the midgut of the Chinese honey bees, Apis
}

Received: 05 July 2016

Accepted: 23 December 2016

Published: 31 January 2017 cerana cerana (Hymenoptera, Apidae)

Hui-Ru Jia ${ }^{1,2}$, Ping-Li Dai ${ }^{1}$, Li-Li Geng ${ }^{2}$, Cameron J. Jack ${ }^{3}$, Yun-He Li ${ }^{2}$, Yan-Yan Wu ${ }^{1}$, Qing-Yun Diao ${ }^{1} \&$ James D. Ellis ${ }^{3}$

Crylle protein derived from Bacillus thuringiensis $(\mathrm{Bt})$ has been proposed as a promising candidate for the development of a new Bt-maize variety to control maize pests in China. We studied the response of the midgut bacterial community of A pis cerana cerana to Cry1le toxin under laboratory conditions. Newly emerged bees were fed one of the following treatments for 15 and 30 days: three concentrations of Cry1le toxin $(20 \mathrm{ng} / \mathrm{mL}, 200 \mathrm{ng} / \mathrm{mL}$, and $20 \mu \mathrm{g} / \mathrm{mL})$ in sugar syrup, pure sugar syrup as a negative control and $48 \mathrm{ng} / \mathrm{mL}$ imidacloprid as a positive control. The relative abundance of $16 \mathrm{~S} \mathrm{rRNA}$ genes was measured by Quantitative Polymerase Chain Reaction and no apparent differences were found among treatments for any of these counts at any time point. Furthermore, the midgut bacterial structure and compositions were determined using high-throughput sequencing targeting the V3-V4 regions of the $16 \mathrm{~S}$ rDNA. All core honey bee intestinal bacterial genera such as Lactobacillus, Bifidobacterium, Snodgrassella, and Gilliamella were detected, and no significant changes were found in the species diversity and richness for any bacterial taxa among treatments at different time points. These results suggest that Cry1le toxin may not affect gut bacterial communities of Chinese honey bees.

The application of Bt plants create considerable environmental and economic benefits in terms of drastic decreases in conventional insecticide use, thus increasing farmer incomes ${ }^{1-3}$. However, Bt plants still give rise to a considerable amount of public debate despite that these toxins have been used for years and numerous studies have supported their safety for both animals and the environment ${ }^{4,5}$. One major concern is the risk of valued non-target organisms feeding on or visiting the Bt plants ${ }^{6}$.

As the most important worldwide pollinator, honey bees play a significant role in maintaining biodiversity and economic development ${ }^{7}$. Because they can feed on pollen from genetically modified (GM) plants expressing toxins, honey bees are exposed to the insecticidal protein ${ }^{8}$. Therefore, the honey bee has been recognized as a crucial non-target organism in the environmental risk assessment process for Bt plants ${ }^{9}$. Honey bee feeding tests with Cry toxins have been performed extensively in laboratory and field settings. The majority of studies focused on these parameters: bee longevity, consumption rates of treated food, development of hypopharyngeal glands, feeding and learning behavior, and superoxide dimutase activity. The evidences demonstrated no negative effect of Cry toxins on any of these parameters observed ${ }^{10-19}$.

Recently, accumulating evidence shows that intestinal microbiota plays a vital role in honey bee nutrient provisioning, pathogen defense and digestive efficiency, neutralization of dietary toxins and its balance is linked to health status of the host ${ }^{20-22}$. Thus, intestinal microbiota abundance and diversity have been used as parameters on which the impact of GM plants on many animals and honey bees have been tested ${ }^{23-28}$.

${ }^{1}$ Ministry Key Laboratory of Pollinating Insect Biology, Institute of Apicultural Research, Chinese Academy of Agricultural Sciences, Beijing 100093, China. ${ }^{2}$ State Key Laboratory for Biology of Plant Diseases and Insect Pests, Institute of Plant Protection, Chinese Academy of Agricultural Sciences, Beijing 100193, China. ${ }^{3}$ Honey Bee Research and Extension Laboratory, Department of Entomology and Nematology, University of Florida, Gainesville, Florida 32611, USA. Correspondence and requests for materials should be addressed to P.-L.D. (email: daipingli@caas.cn) 
A

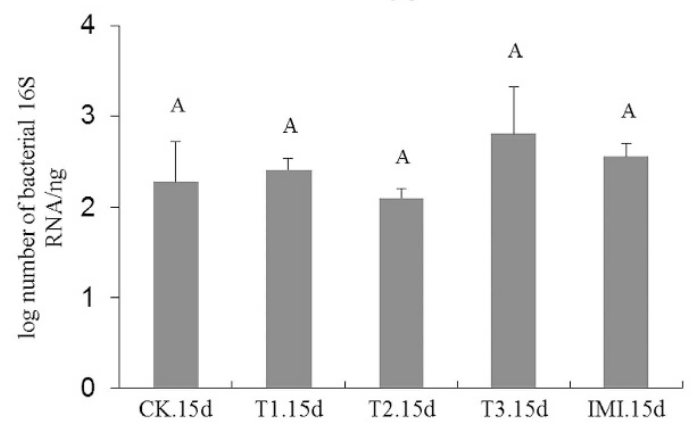

B

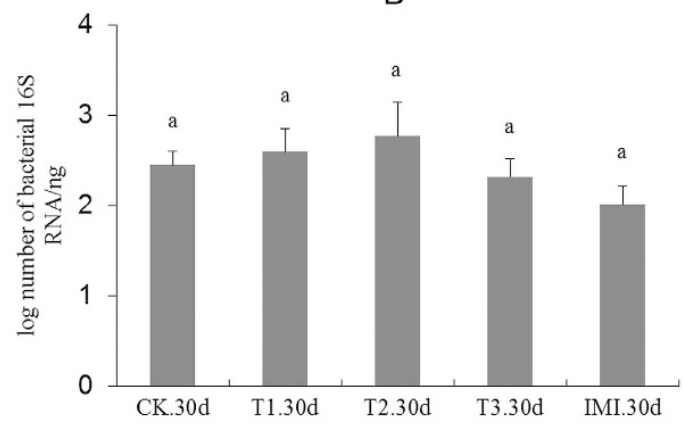

Figure 1. Log-transformed abundance of the $16 \mathrm{~S}$ rRNA gene across different treatments at two sampling times. CK - Pure sugar syrup, T1-20 ng/mL Cry1le toxin syrups, T2-200 ng/mL Cry1le toxin syrups, T3-20 $\mu \mathrm{g} / \mathrm{mL}$ Crylle toxin syrups; IMI- $48 \mathrm{ng} / \mathrm{mL}$ imidacloprid syrups. Bars with the same letter are not statistically different at $\alpha \leq 0.05$ as determined by Tukey's HSD analysis.

Crylle is a novel toxin with a different insecticidal mechanism from that of other Bt toxins currently applied for pest control purposes. This may help to delay the evolution of insect resistance to Bt toxins ${ }^{29,30}$. Some investigators have confirmed that Crylle may be a good candidate to be produced in new commercial Bt variety for pest control ${ }^{31-33}$. However, except for two recent studies that have assessed the effect of CrylIe toxin on Western honey bee (Apis mellifera ligustica) under laboratory conditions ${ }^{18,28}$, the impacts of Crylle toxin on honey bees are poorly understood.

The Asian honey bee, Apis cerana, is a honey bee species indigenous to Asia and is the second most populous honey bee species in China ${ }^{34}$. Compared to western honey bees ( $A$. mellifera) which are the most abundant bee species managed in China, A. cerana has many unique characteristics that make them useful pollinators; including better adaptability to local climate, disease resistance and the ability of utilizing scattered nectar ${ }^{35,36}$. Thus, proper risk assessment of any new Bt toxin on this species is indispensable, especially for China. However, studies evaluating the effects of Crylle toxin on Chinese honey bees, Apis cerana cerana, are scarce. Here, we used midgut bacterial community as a parameter to identify the impacts of Crylle toxin on Chinese honey bees, Apis cerana cerana, through next-generation sequencing technology on the MiSeq platform.

\section{Results}

Changes in bacterial 16S rRNA gene abundance. The bacterial abundance was characterized by calculating $16 \mathrm{~S}$ rRNA gene copy numbers using an absolute quantification qPCR method. For quantifying the copy numbers, a standard curve of $y=-0.3628 x+10.3199$ ( $y=$ the logarithm of plasmid copy number to base 2 , $\mathrm{x}=\mathrm{Ct}$ value, $\mathrm{R}^{2}=0.995$ ) was established as shown in Fig. S2. The copy number of $16 \mathrm{~S}$ rRNA gene in each sample was calculated based on the standard curve (Table S1), then log-transformed prior to statistical analysis to satisfy the normality assumptions. The log10-transformed the copy numbers across different treatments are shown in Fig. 1, and these values were not significantly different among different treatments at any sample time $(\mathrm{P}>0.05$, Table S2). These results suggest that dietary Cry1Ie toxin has no significant impact on honey bee midgut bacterial abundance.

Intestinal bacterial communities of adult Chinese honey bees. In the current study, we characterized the Chinese honey bee midgut bacterial community via 16S rRNA amplicons sequencing on Illumina MiSeq platform. Paired-end sequencing of $16 \mathrm{~S}$ rRNA V3-V4 gene produced a total of 2,071,950 raw sequences from 30 samples. After trimming the barcodes, primers and filtering chimeras, short and low-quality reads, 53,372 effective sequences were obtained, ranging from 29,264 to 64,739 per sample, and the average length of effective sequences reads was $419 \mathrm{bp}$ (Table S3). All valid sequences were normalized for further analysis. However, rarefaction analyses showed that the number of observed species did not approach saturation (Fig. S3), even after 30,000 sequences, which means that more sequencing efforts were needed to capture more species.

To identify the phylogenetic diversity of midgut bacterial communities in Chinese honey bees, all effective reads were classified into different taxonomies (phylum, class, order, family, and genera levels) according to the QIIME using default settings, and the taxonomic distribution at different levels were summarized in Fig. 2. Overall, these bacterial taxa were dominant in all treatments $(>1 \%): 3$ phyla (Proteobacteria, Firmicutes and Actinobacteria), 5 classes (Alphaproteobacteria, Betaproteobacteria, Gammaproteobacteria, Bacilli, and Actinobacteria), 6 orders (Rhodospirillales, Lactobacillales, Neisseriales, Orbales, Rhizobiales, and Enterobacteriales), 7 families (Acetobacteraceae, Neisseriaceae, Lactobacillaceae, Orbaceae, Bartonellaceae, Enterobacteriaceae, and Bifidobacteriaceae), and 8 genera (Commensalibacter, Lactobacillus, Snodgrassella, Gilliamella, Frischella, Saccharibacter, Bifidobacterium and Bartonella).

Based on the average relative abundance, Proteobacteria (70\%) was the most abundant phyla among the classified bacterial phyla. The classes with the highest abundance of bacteria were $\alpha$-Proteobacteria (36.47\%), Bacilli (25.41\%), $\beta$-Proteobacteria (20.48\%), and $\gamma$-Proteobacteria (14.92\%). Commensalibacter of the family of Acetobacteraceae (28.65\%), followed by Lactobacillus (25.31\%), Snodgrassella (20.44\%), were the 3 most abundant genera found. 

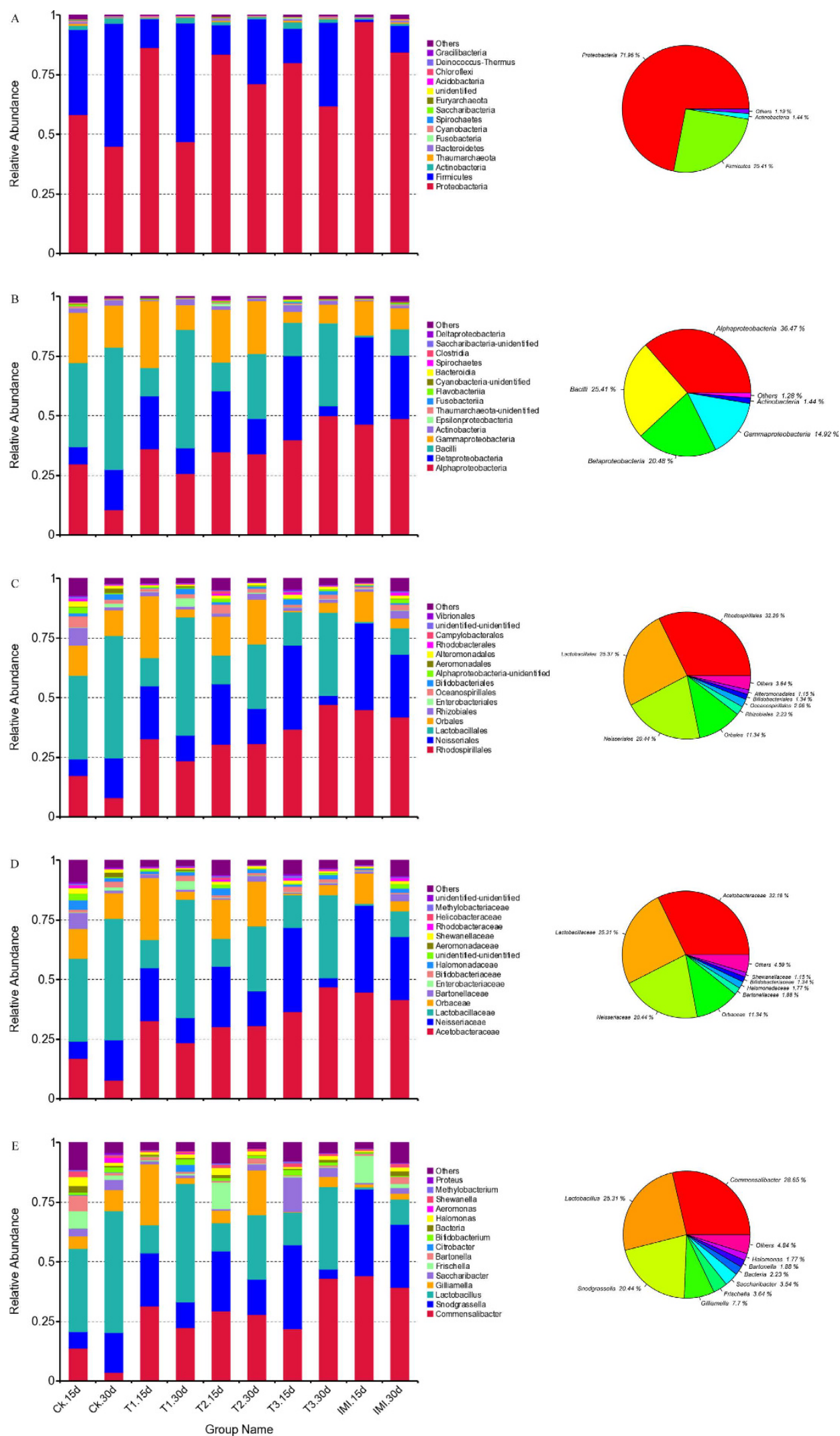

Figure 2. Relative abundance of the dominant midgut bacterial communities in Chinese honey bees (Apis cerana cerana) at phylum (A), class (B), order (C), family (D), and genera (E) levels. Each bar represents the average relative abundance of each bacterial taxon within a group. CK - Pure sugar syrup, T1-20 ng/mL Cry1Ie toxin syrups, T2-200 ng/mL Cry1Ie toxin syrups, T3-20 $\mu \mathrm{g} / \mathrm{mL}$ Cry1Ie toxin syrups; IMI- $48 \mathrm{ng} / \mathrm{mL}$ imidacloprid syrups. 

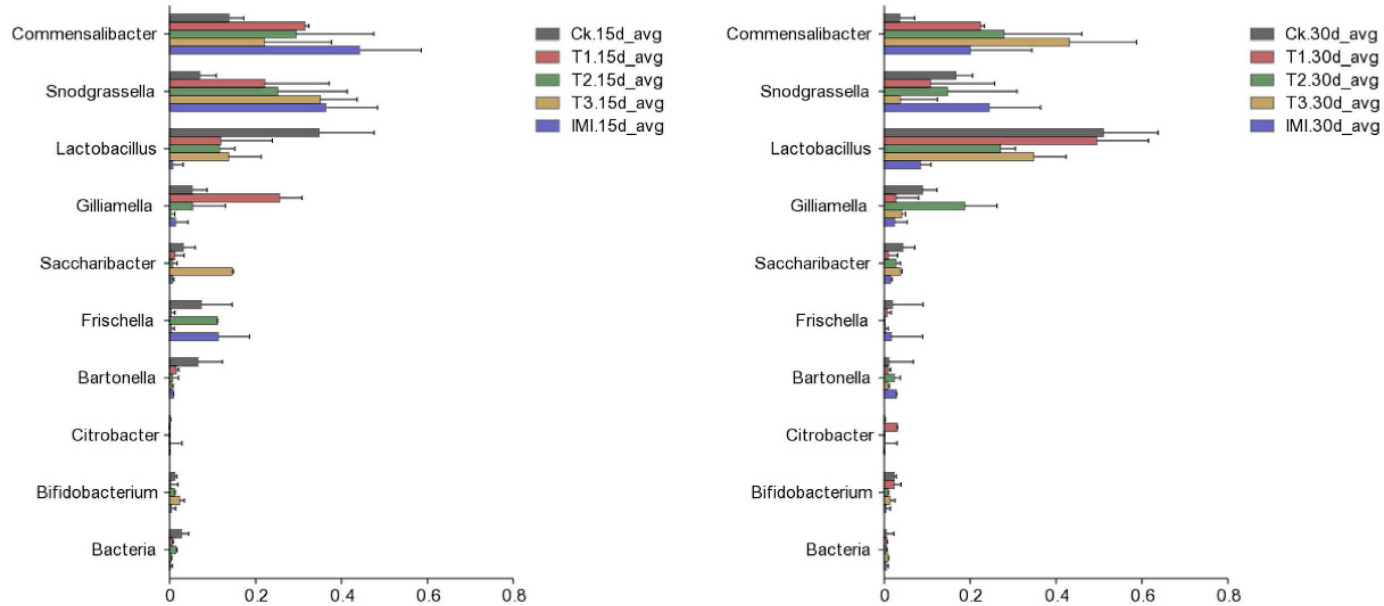

Figure 3. The relative abundance of the 10 most abundant bacteria genera in the midgut of Chinese honey bee (Apis cerana cerana) adults across the five treatments at two sampling times. Horizontal bars represent the standard error of the means composed of three replicates.

Effects of the Bt Crylle toxin on the midgut bacterial composition of Chinese honey bees. To determine the changes in the midgut bacterial communities of Chinese honey bees fed Crylle toxin, a statistical analysis for the relative abundances of the 10 most abundant genera were conducted using one-way ANOVA (SPSS. 16.0). Among the 10 most abundant bacteria genera were Commensalibacter, Lactobacillus, Snodgrassella, Gilliamella, Frischella, Saccharibacter, Bartonella, Bifidobacterium, Citrobacter, and Bacteria. All were present in all treatment bee groups as major genera $(>1 \%)$ (Table S4), and the histograms of these bacterial taxa are shown in Fig. 3. An analysis on the 10 most abundant genera revealed no significant differences in the relative abundances of any bacterial taxon with respect to the different treatments (Table S5, P > 0.05).

Furthermore, the difference of the midgut microbial community composition in different treatments was evaluated further using Hierarchical cluster analysis. Hierarchically clustered heat maps of all the abundant genera (relative abundance $>1 \%$ ) are shown in Fig. 4. This figure shows that mostly all of the presented bacterial taxa here were clustered together corresponding to different treatments. These results demonstrate that the midgut bacterial composition across the different treatment groups was not significantly different.

Effects of the Bt Cry1le toxin on the midgut bacterial structure of Chinese honey bees. To determine if Chinese honey bee midgut microbiota community structures were altered by the Crylle toxin, the bacterial diversity was analyzed across different treatments. The bacterial diversity was characterized by calculating the alpha diversity parameters (Table S6). Two representatively alpha diversity parameters including observed species (sequencing depth) and the Shannon index (diversity indices), were selected for community richness comparison. Box plots of these richness estimators for individual sample groups are shown in Fig. 5. Comparison diversity indexes among groups were compared using a one-way ANOVA (SPSS. 16.0) with no significant differences in richness noticed across the five treatment groups $(\mathrm{P}>0.05$, Table $\mathrm{S} 7)$.

For a better analysis of the relationships between gut microbiota community structures of the honey bees across the five treatments, the Principal Coordinate Analysis (PCoA) was performed based on the Unifrac metric. A 3-D plot of first principal component (PC1), second principal component (PC2), and third principal component (PC3) obtained by PCoA is shown in Fig. 6 . The plot elucidated the characteristics of four botanical origins of the bacterial communities. The percentages are the percentage of total community variations explained by the components. On the PCoA plot, each symbol represents the gut microbiota of a sample. Sample points that are close together are more similar in community composition than those that are far apart. No significant differences in community structure were observed. The pattern revealed by PCoA were tested further using ANOSIM. Consistent with the PCoA plot, no significant impacts were noticed (Table S8). These data suggest that the midgut bacterial community structures in honey bees are not be influenced by the Bt Crylle toxin.

\section{Discussion}

The potential risk of Bt toxin on the intestinal microbiota on non-target organisms is a major safety concern and requires careful consideration. Several studies have addressed the impact of Bt Cry toxin on honey bee intestinal microbiota; however, investigators in these studies mainly adopted conventional molecular methods, such as terminal restriction fragment length polymorphism (T-RFLP) ${ }^{23,27}$ and polymerase chain reaction-denaturing gradient gel electrophoresis (PCR-DGGE) ${ }^{25,26}$ to investigate the impacts. Many studies claimed that these conventional molecular methods were considered specific, but low-throughput and low sensitivity in characterizing microbial ecology merely provides preliminary information. Thus, the use of these methods to investigate the changes in microbial community structure and diversity cannot provide comprehensive insights to their differences and may result in some bacteria remaining undetected. For instance, previous studies have reported that Lactobacillus plays a significant role in honey bee health and that this genus is one of the core microflora within honey bees ${ }^{37,38}$. 

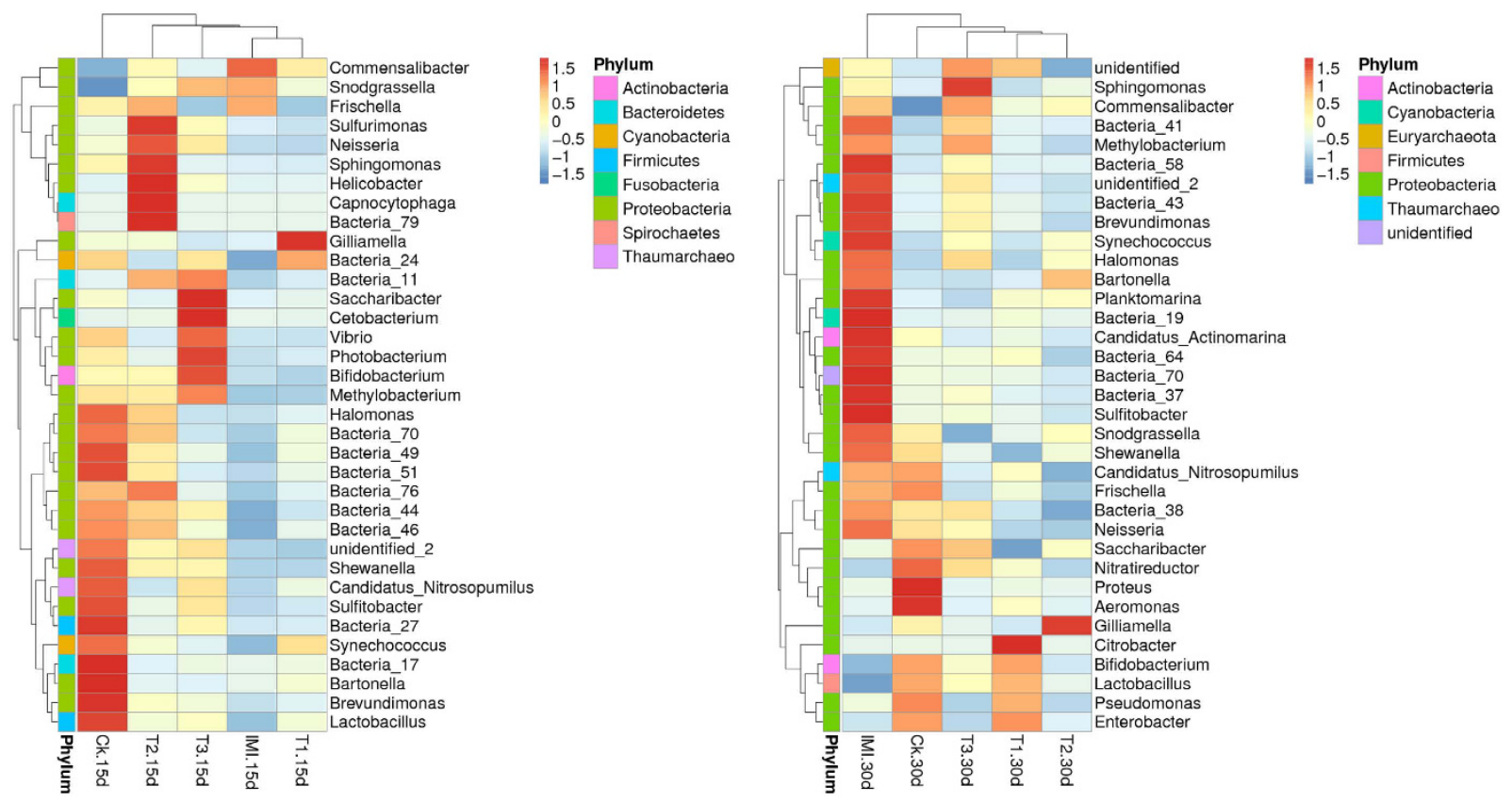

Figure 4. Hierarchically clustered heat map analysis of the highly represented bacterial taxa (at the genus level) found in the midgut of Chinese honey bee (Apis cerana cerana) workers (relative abundance $>1 \%$ ) across the five treatments at two sampling times. The relative percentages (\%) of the bacterial families are indicated by varying color intensities according to the legend at the top of the figure. The color key for the $\mathrm{Z}$ score indicates correspondence between blue-red coloring and standard deviations from the mean abundance of each bacteria. For those bacterial taxa unable to be assigned into specific known bacterial genera, the higher known taxonomic unit was added: Bacteria_11 (c_Actinobacteria); Bacteria_17 (f_Flammeovirgaceae); Bacteria_19 (f_Flavobacteriaceae); Bacteria_24 (o_Ignavibacteriales); Bacteria_27 (p_Cyanobacteria); Bacteria_37 (f_Gemmatimonadaceae); Bacteria_38 (c_Gemmatimonadetes); Bacteria_41 (c_Oligosphaeria); Bacteria_43 (c_Phycisphaerae); Bacteria_44 (Planctomycetaceae); Bacteria_46 (f_Hyphomonadaceae); Bacteria_49 (f_Hyphomonadaceae); Bacteria_51 (f_Acetobacteraceae); Bacteria_58 (f_Alcaligenaceae); Bacteria_64 (f_Rhodocyclaceae); Bacteria_70 (f_Sandaracinaceae); Bacteria_76 (f_Chromatiaceae); Bacteria_79 (f_Coxiellaceae).

However, when PCR-DGGE was used, Lactobacillus was not detected during a study on the influence of transgenic cry $1 \mathrm{Ah}$ maize pollen on the midgut bacteria community of the Chinese honey bee ${ }^{25}$.

As molecular biological technology continues to develop, some burgeoning technologies such as high-throughput sequencing is being applied frequently to characterize microbial ecology, including in the honey bee intestinal microbiota ${ }^{20,28,39-42}$. These technologies have many benefits including high sensitivity, high accuracy and short processing times ${ }^{43,44}$. Moreover, these approaches have enough sequencing depth to cover complex bacterial communities, and the diversity in microbial populations is significantly higher than previously estimated by earlier conventional molecular methods ${ }^{45,46}$. In previous work, this method has been first applied into the CrylIe toxin risk assessment of another bee species A.mellifer ${ }^{28}$. In the current study, a 16S rRNA amplicons sequencing method was also used to examine the potential effects of Crylle toxin on the midgut bacterial communities of Chinese honey bees. Our findings correspond with our previous reports that neither the midgut bacterial diversity nor their compositions were affected when the bees were exposed to Crylle toxin ${ }^{28}$. These results suggest that Crylle does not impact the gut bacterial communities of honey bees.

Honey bee intestinal microbiota has been extensively investigated using both culture-dependent and culture-independent methods. In this study, we also characterized the dominant midgut bacteria of Chinese honey bees through Illumina MiSeq paired-end sequencing of 16S rRNA gene, which were Commensalibacter, Lactobacillus, Snodgrassella, Gilliamella, Frischella, Saccharibacter, Bartonella, Bifidobacterium and Citrobacter from $\alpha-, \beta-, \gamma$-Proteobacteria, Firmicutes and Actinobacteria. In agreement with previously published results ${ }^{20,42}$, all these conserved bacterial groups have been found in Chinese honey bees in our study. Reports indicate that adult honey bee worker guts are dominated by a few specific gut bacterial groups; merely the proportions of these phylotypes differ depending on diet and species ${ }^{47,48}$. For instance, a previous study investigated the intestinal microbiota of another bee species (A.mellifera), $\gamma$-Proteobacteria was the most common group of bacteria ${ }^{28}$; while, in this study, the most abundant group of bacteria was $\alpha$-Proteobacteria.

Interestingly, the Commensalibacter was the most abundant bacterial genus in this study and its abundance was much higher than previously described. This genus belongs to the family Acetobacteraceae which is commonly found as commensal bacteria in many insects, including the honey bee ${ }^{49}$. Recent studies suggest this genus is a major intestinal symbiont involved in many key functions of the host, such as immunity, metabolism, and growth $^{49-52}$. Earlier researchers have suggested that populations of this bacterial taxon rely on sugar-rich diets ${ }^{49}$, 

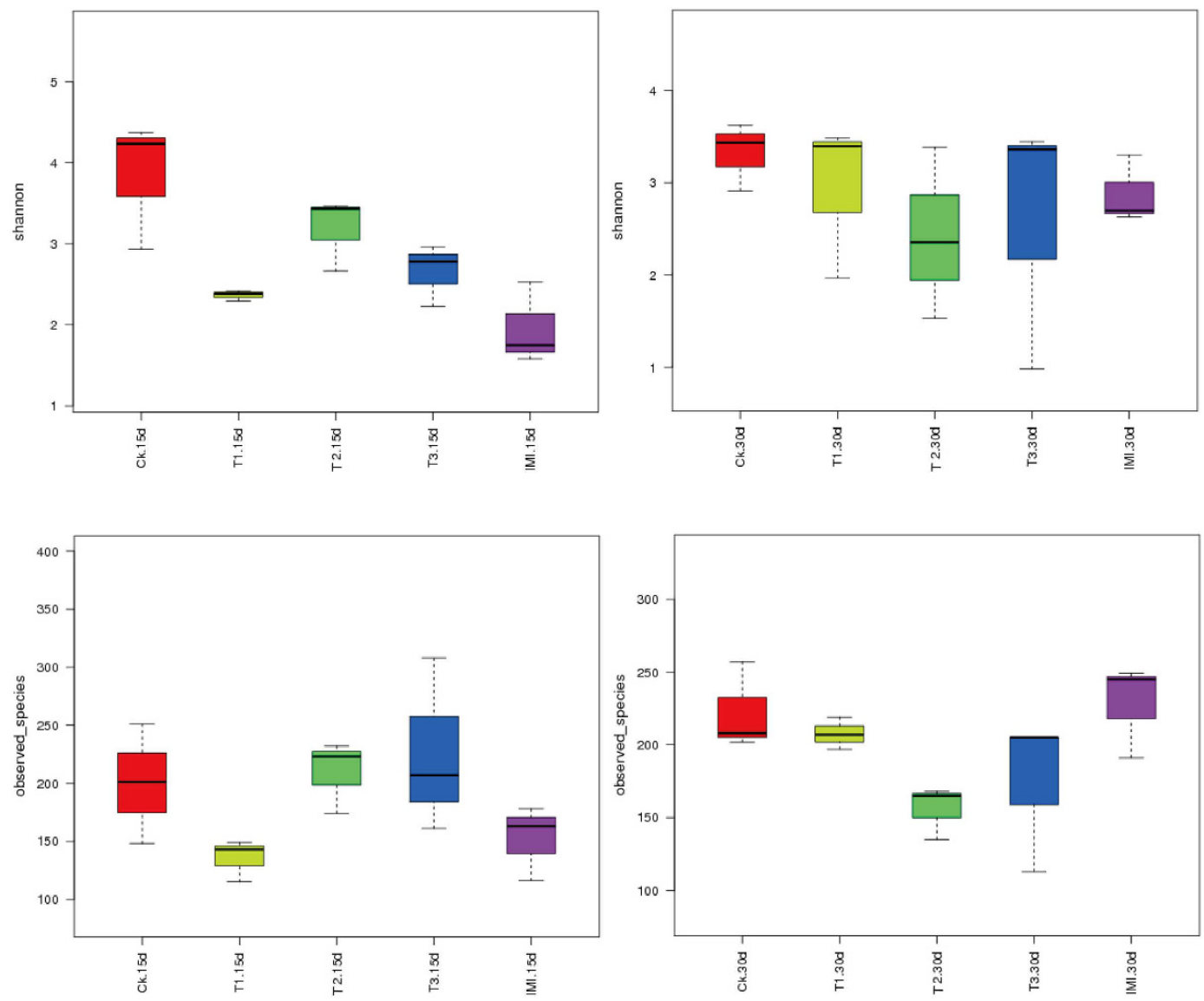

Figure 5. Box plot of mean alpha diversity for the five treatments at two sampling times. Error bars indicate standard errors.
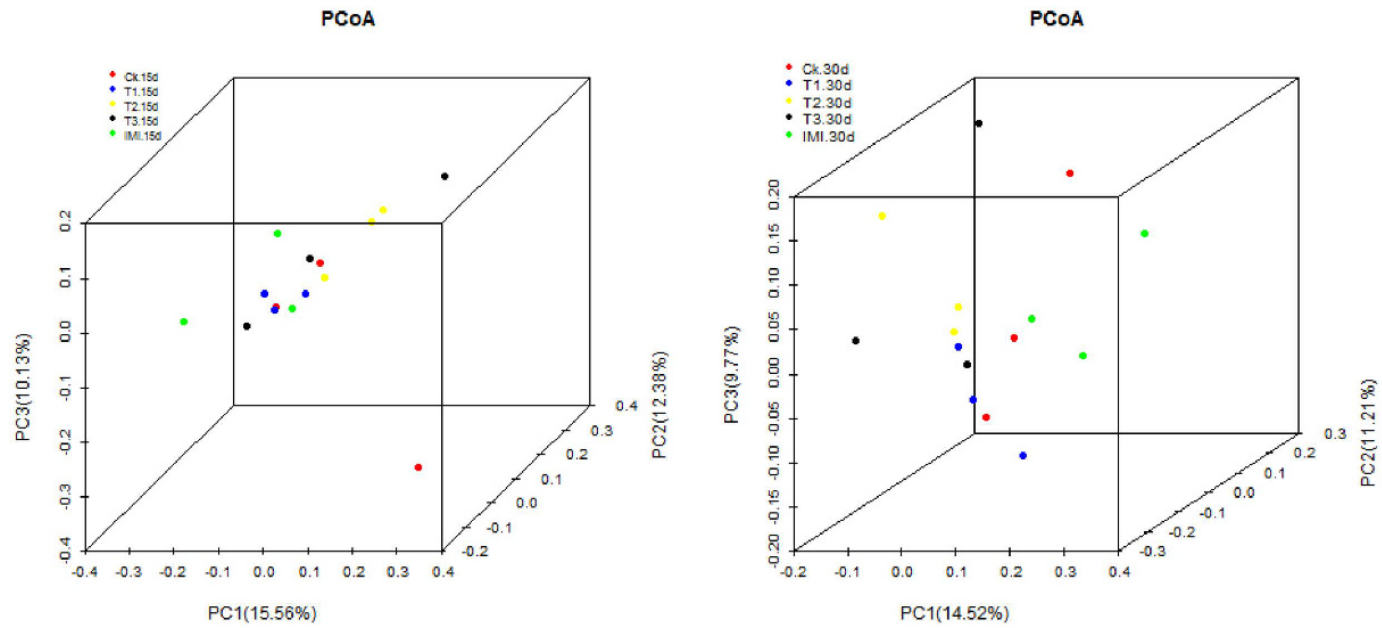

Figure 6. 3-D score plot for the three principal components of the midgut microbiota among five treatments at two sampling times. Each symbol represents each sample gut microbiota.

so the high levels of Commensalibacter in our study is probably related to the sugar diets fed to honey bees in the laboratory and may not accurately reflect the Commensalibacter levels found naturally in A. cerana.

In the current study, we used qPCR and high-throughput sequencing to assess the effects of Crylle toxin on the midgut bacterial community of Chinese honey bees. No significant differences in the midgut bacterial abundance and composition were observed among the treatments and thus, we conclude that Crylle does not affect bacterial diversity in the midguts of Chinese honey bees. Our work establishes a foundation leading to increased understanding of the effects of this toxin on honey bees and provides laboratory-based evidence for its future use 
in transgenic plants to control insect pests. However, laboratory research is merely the first step of the biosafety assessment of a transgenic crop ${ }^{53,54}$. In order to provide a comprehensive risk assessment, future work under more realistic conditions (i.e., bees fed on GM pollen or field trials) is needed.

\section{Methods}

Honey bees and Cry1le toxin. Honey bee queens were caged on a brood comb to achieve a uniform age. The combs containing nine-day old capped Chinese honey bee pupae, were brought from apparently healthy colonies located at the Department of Bee Protection and Biological Safety, Institute of Apicultural Research, Chinese Academy of Agricultural Sciences (CAAS), Beijing, China $\left(40^{\circ} 00^{\prime} 28^{\prime \prime} \mathrm{N}, 116^{\circ} 12^{\prime} 18^{\prime \prime} \mathrm{E}\right)$. The brood combs were placed in the incubator at $34 \pm 1{ }^{\circ} \mathrm{C}$. All experimental work was conducted in June of 2015 .

The Crylle toxin used in the experiments was kindly provided by Prof. Jie Zhang from the State Key Laboratory for Biology of Plant Diseases and Insect Pests, the Institute of Plant Protection, CAAS, Beijing, China. The toxin was stored at $-20^{\circ} \mathrm{C}$ and mixed thoroughly with sugar syrup $(60 \% \mathrm{w} / \mathrm{v}$ sucrose solution) to obtain the desired concentrations in our study $(20 \mathrm{ng} / \mathrm{mL}, 200 \mathrm{ng} / \mathrm{mL}$, and $20 \mu \mathrm{g} / \mathrm{mL})$.

Experimental design and laboratory feeding of honey bees. Newly emerged adult bees $(<6 \mathrm{~h}$ old) were collected from these frames and randomly placed into wooden, mesh-sided cages (dimensions of $10 \mathrm{~cm} \times 7 \mathrm{~cm} \times 8 \mathrm{~cm}$ ) (Fig. S1). Each cage contained 30 bees and all cages were randomly assigned to the different treatment groups and maintained in a dark incubator $\left(30 \pm 1{ }^{\circ} \mathrm{C}, 60 \pm 10 \%\right.$ relative humidity) until the end of the experiment. In the study, honey bees were exposed to CrylIe toxin via an artificial sucrose diet. Altogether, there were five defined diets which included pure sugar syrup $(60 \% \mathrm{w} / \mathrm{v}$ sucrose solution, the negative control), three concentrations of Crylle toxin $(20 \mathrm{ng} / \mathrm{mL}, 200 \mathrm{ng} / \mathrm{mL} \text {, and } 20 \mu \mathrm{g} / \mathrm{mL})^{18}$ and $48 \mathrm{ng} / \mathrm{mL}$ imidacloprid syrup, the positive control ${ }^{55}$. There were three replicates for each treatment. A surplus of pollen and treatment syrup were fed ad libitum and were replaced daily until further honey bee dissection and DNA extraction.

Honey bee dissection and DNA extraction. After 15 and $30 \mathrm{~d}$ of exposure to treatments, 5 bees were randomly removed from each cage. These bees were placed in the freezer at $-20^{\circ} \mathrm{C}$ for $10 \mathrm{~s}$ to render them inactive, and their midguts were isolated on ice using sterile forceps. Dissected midguts from the same treatment group were pooled in a $2 \mathrm{~mL}$ eppendorf tube and immediately frozen in liquid nitrogen for subsequent DNA extraction.

The total midgut bacterial DNA from each sample was extracted with a QIAamp DNA Stool Mini Kit (Qiagen, catalogue number 51504, Hilden, Germany) according to the manufacturer's protocol. The concentration and purity of the obtained DNA were evaluated using the Nanodrop ND 2000 (Nanodrop Technologies, Wilmington, DE, USA).

Quantitative polymerase chain reaction (qPCR). The bacterial $16 \mathrm{~S}$ rRNA gene was quantified by qPCR on an ABI7500 PCR System (Applied Biosystems, Carlsbad, CA, USA) applying the universal bacterial primer pairs BAC27F/ BAC355R ${ }^{56}$. The $\mathrm{qPCR}$ reactions were performed in a $20 \mu \mathrm{L}$ volume containing $10 \mu \mathrm{L} 2 \mathrm{x}$ Es Taq MasterMix, $0.5 \mu \mathrm{L}$ of each primer $(10 \mu \mathrm{M}), 1 \mu \mathrm{L}$ of five-fold diluted template DNA template, and $8 \mu \mathrm{L}$ of sterilized $\mathrm{H}_{2} \mathrm{O}$. Amplification conditions were as follows: an initial denaturation of $3 \mathrm{~min}$ at $95^{\circ} \mathrm{C}$; five touch-down cycles of $20 \mathrm{~s}$ at $95^{\circ} \mathrm{C}, 10 \mathrm{~s}$ from $65^{\circ} \mathrm{C}$ to $60^{\circ} \mathrm{C}, 20 \mathrm{~s}$ at $68^{\circ} \mathrm{C}$, followed by 38 cycles of $15 \mathrm{~s}$ at $95^{\circ} \mathrm{C}, 15 \mathrm{~s}$ at $58^{\circ} \mathrm{C}$, and $20 \mathrm{~s}$ at $68^{\circ} \mathrm{C}$. In order to avert technical error, each qPCR reaction for all test samples was performed in triplicate. Standard curves were constructed from 10 -fold serial dilutions of plasmid containing the cloned target genes. 16S rRNA gene copy numbers in test samples were calculated by linear regression of the normalized sample Ct values to the standard curve.

MiSeq sequencing of 16S rRNA gene amplicons. The V3-V4 region of the bacterial 16S rRNA gene was targeted with the barcoded primer pair $341 \mathrm{f} / 806 \mathrm{r}$ (341 F: CCTAYGGGRBGCASCAG, $806 \mathrm{R}$ : GGACTACNNGGGTATCTAAT) for the microbial community diversity analysis ${ }^{57,58}$. All PCR reactions in a $30 \mu \mathrm{L}$ mixture contained $15 \mu \mathrm{L} 2 \times$ Phusion Master Mix (New England Biolabs, USA), $1 \mu \mathrm{L}$ of forward and reverse primers, and about $10 \mathrm{ng}$ DNA template. Amplification conditions were as follows: initial denaturation at $98^{\circ} \mathrm{C}$ for $1 \mathrm{~min}$, followed by $35 \mathrm{cycles}$ of denaturation at $98^{\circ} \mathrm{C}$ for $10 \mathrm{~s}$, annealing at $50^{\circ} \mathrm{C}$ for $30 \mathrm{~s}$, extension at $72^{\circ} \mathrm{C}$ for $30 \mathrm{~s}$, and a final extension step at $72^{\circ} \mathrm{C}$ for $5 \mathrm{~min}$. The PCR products were checked by electrophoresis on $2 \%$ agarose gels and purified with GeneJET Gel Extraction Kit (Thermo Scientific). Finally, according to protocols described by Caporaso ${ }^{58}$, the purified products were sequenced on the Illumina MiSeq 250 platform (Illumina, San Diego, CA, USA) at Novogene Bioinformatics Technology Co., Ltd, Beijing, China.

Data analysis. Paired-end reads were assigned to samples according to the unique barcode of each sample. After cutting off the barcode and primer sequence, the reads that were shorter than twice the length of reads were merged into single, longer sequences using FLASH v1.2.7 (http://ccb.jhu.edu/software/FLASH/) ${ }^{59}$. The splicing sequences were called "raw reads". The low-quality sequences (shorter than $200 \mathrm{bp}$, average quality value of $<25$ ) and the chimera sequences then were filtered out from downstream analysis using QIIME V1.7.0 software package (http://qiime.org/index.html) ${ }^{60}$ and UCHIME algorithm (http://www.drive5.com/usearch/manual/uchime algo.html $)^{61}$ with the default parameters. The obtained sequences were called "clean reads" and normalized to make the samples compared at the same sequencing depth for the following analysis.

These normalized sequences were classified into operational taxonomic units (OTUs) at $97 \%$ similarity using UPARSE pipeline v7.0.1001 (http://drive5.com/uparse//62. The taxonomy of the OTUs was assigned by blasting against SILVA SSU database $119^{63,64}$ with default parameters. Alpha diversity included Shannon index and observed species of each sample and beta diversity included both unweighted and weighted Unifrac distances between samples, were performed with QIIME (Version 1.7.0) and displayed with R software (Version 2.15.3). 
Statistical analysis. To determine whether the composition and structure of midgut bacterial communities differed significantly among treatments, statistical comparisons were made across different treatments on the 16S rRNA gene copy numbers, the dominant midgut bacterial genera composition and the richness estimators. The bacterial counts and relative abundance values were normalized with log-transformations to the base 10 prior to statistical analysis. All statistical analyses were conducted between each treatment with one-way analysis of variance (ANOVA) followed by Tukey's HSD using the software package SPSS 16.0 (IBM Co., Armonk, NY, USA).

\section{References}

1. Wu, K. M., Lu, Y. H., Feng, H. Q., Jiang, Y. Y. \& Zhao, J. Z. Suppression of cotton bollworm in multiple crops in China in areas with Bt toxin containing cotton. Science 321, 1676-1678 (2008).

2. Tabashnik, B. E. Communal benefits of transgenic corn. Science 330, 189-190 (2010).

3. Lu, Y. H., Wu, K. M., Jiang, Y. Y., Guo, Y. Y. \& Desneux, N. Widespread adoption of Bt cotton and insecticide decrease promotes biocontrol services. Nature 487, 362-365 (2012).

4. Mendelsohn, M., Kough, J., Vaituzis, Z. \& Matthews, K. Are Bt crops safe? Nat. Biotechnol. 21, 1003-1009 (2003).

5. Randhawa, G. J., Singh, M. \& Grover, M. Bioinformatic analysis for allergenicity assessment of Bacillus thuringiensis Cry proteins expressed in insect-resistant food crops. Food Chem. Toxicol. 49, 356-362 (2011).

6. Romeis, J. et al. Assessment of risk of insect-resistant transgenic crops to non-target arthropods. Nat. Biotechnol. 26, 203-208 (2008).

7. Klein, A. M. et al. Importance of pollinators in changing landscapes for world crops. Proc. Biol. Soc. B 274, 303-313 (2007).

8. Malone, L. A. \& Pham-Delègue, M. H. Effects of transgene products on honey bees (Apis mellifera) and bumblebees (Bombus sp.). Apidologie 32, 287-304 (2001).

9. Duan, J. J., Marvier, M., Huesing, J., Dively, G. \& Huang, Z. Y. A meta-analysis of effects of Bt crops on honey bees (Hymenoptera: Apidae). PloS One 1, e1415 (2008).

10. Malone, L., Todd, J., Burgess, E. \& Christeller, J. Development of hypopharyngeal glands in adult honey bees fed with a Bt toxin, a biotin-binding protein and a protease inhibitor. Apidologie 35, 655-664 (2004).

11. Ramirez-Romero, R., Desneux, N., Decourtye, A., Chaffiol, A. \& Pham-Delègue, M. H. Does Cry1Ab protein affect learning performances of the honey bee Apis mellifera L. (Hymenoptera, Apidae)? Ecotoxicol. Environ. Saf. 70, 327-333 (2008).

12. Han, P., Niu, C. Y., Lei, C. L., Cui, J. J. \& Desneux, N. Use of an innovative T-tube maze assay and the proboscis extension response assay to assess sublethal effects of GM products and pesticides on learning capacity of the honey bee Apis mellifera L. Ecotoxicology 19, 1612-1619 (2010).

13. Han, P., Niu, C. Y., Biondi, A. \& Desneux, N. Does transgenic Cry1Ac+ CpTI cotton pollen affect hypopharyngeal gland development and midgut proteolytic enzyme activity in the honey bee Apis mellifera L. (Hymenoptera, Apidae)? Ecotoxicology 21, 2214-2221 (2012).

14. Han, P., Velasco-Hernández, M. C., Ramirez-Romero, R. \& Desneux, N. Behavioral effects of insect-resistant genetically modified crops on phytophagous and beneficial arthropods: a review. J. Pest Sci. 89, 859-883 (2016).

15. Dai, P. L. et al. Field assessment of Bt cry1Ah corn pollen on the survival, development and behavior of Apis mellifera ligustica. Ecotoxicol. Environ. Saf. 79, 232-237 (2012).

16. Dai, P. L. et al. The effects of Bt Cry1Ah toxin on worker honeybees (Apis mellifera ligustica and Apis cerana cerana). Apidologie 43, 384-391 (2012)

17. Dai, P. L. et al. Effects of Bt crylAh corn pollen on immature worker survival and development of Apis cerana cerana. J. Apic. Res. 54, 72-76 (2015).

18. Dai, P. L., Jia, H. R., Geng, L. L. \& Diao, Q. Y. Bt toxin Crylle causes no negative effects on survival, pollen consumption, or olfactory learning in worker honey bees (Hymenoptera: Apidae). J Econ. Entomol. 109, 1028-1033 (2016).

19. Wang, Y. Y. et al. Toxicological, biochemical, and histopathological analyses demonstrating that Cry $1 \mathrm{C}$ and Cry $2 \mathrm{~A}$ are not toxic to larvae of the honeybee, Apis mellifera. J. Agric. Food Chem. 63, 6126-6132 (2015).

20. Engel, P., Martinson, V. G. \& Moran, N. A. Functional diversity within the simple gut microbiota of the honey bee. Proc. Natl. Acad. Sci. 109, 11002-11007 (2012).

21. Kwong, W. K., Engel, P., Koch, H. \& Moran, N. A. Genomics and host specialization of honey bee and bumble bee gut symbionts. Proc. Natl. Acad. Sci. 111, $11509-11514$ (2014).

22. Lee, F. J., Rusch, D. B., Stewart, F. J., Mattila, H. R. \& Newton, I. L. G. Saccharide breakdown and fermentation by the honey bee gut microbiome. Environ. Microbiol. 17, 796-815 (2015).

23. Babendreier, D., Joller, D., Romeis, J., Bigler, F. \& Widmer, F. Bacterial community structures in honeybee intestines and their response to two insecticidal proteins. FEMS Microbiol. Ecol. 59, 600-610 (2007).

24. Desneux, N., Ramírez-Romero, R., Bokonon-Ganta, A. H. \& Bernal, J. S. Attraction of the parasitoid Cotesia marginiventris to host (Spodoptera frugiperda) frass is affected by transgenic maize. Ecotoxicology 19, 1183-1192 (2010).

25. Jiang, W. Y. et al. The influence of Bt-transgenic maize pollen on the bacterial diversity in the midgut of Chinese honeybees, Apis cerana cerana. J. Integr. Agric. 12, 474-482 (2013).

26. Geng, L. L. et al. The influence of Bt-transgenic maize pollen on the bacterial diversity in the midgut of Apis mellifera ligustica. Apidologie 44, 198-208 (2013).

27. Hendriksma, H. P. et al. Effect of stacked insecticidal Cry proteins from maize pollen on nurse bees (Apis mellifera carnica) and their gut bacteria. PloS One 8, e59589 (2013).

28. Jia, H. R. et al. The effects of Bt CrylIe toxin on bacterial diversity in the midgut of Apis mellifera ligustica (Hymenoptera: Apidae). Sci. Rep. 6, 24664 (2016).

29. Song, F. et al. Identification of cry1I-type genes from Bacillus thuringiensis strains and characterization of a novel cry1I-type gene. Appl. Environ. Microbiol. 69, 5207-5211 (2003).

30. Liu, Y. J. et al. Expression of a modified crylIe gene in E. coli and in transgenic tobacco confers resistance to corn borer. Acta Biochim. Biophys. Sin. 36, 309-313 (2004).

31. Guo, S. et al. Purification of an active fragment of CrylIe toxin from Bacillus thuringiensis. Protein Expr. Purif. 78, 204-208 (2011).

32. Zhang, Y. et al. Overexpression of a novel Cry1Ie gene confers resistance to CrylAc-resistant cotton bollworm in transgenic lines of maize. Plant Cell Tissue Organ Cult. 115, 151-158 (2013).

33. Zhang, Y. et al. Assessment of transgene copy number and zygosity of transgenic maize over expressing Crylle gene with SYBR ${ }^{\circledR}$ Green qRT-PCR. In Vitro Cell. Dev. Biol. Plant. 51, 125-134 (2015).

34. Yang, W. et al. Comparative sucrose responsiveness in Apis mellifera and A. cerana foragers. PLoS One 8, e79026 (2013).

35. Anderson, D. L. \& Trueman, J. W. H. Varroa jacobsoni (Acari: Varroidae) is more than one species. Exp Appl Acarol 24, 165-189 (2000).

36. Yang, G. H. Harm of introducing the western honeybee Apis mellifera L. to the Chinese honeybee Apis cerana F. and its ecological impact. Acta Entomol. Sin. 48, 401-406 (2005).

37. Vásquez, A. et al. Symbionts as major modulators of insect health: lactic acid bacteria and honeybees. PLoS One 7, e33188 (2012).

38. Evans, J. D. \& Lopez, D. L. Bacterial probiotics induce an immune response in the honey bee (Hymenoptera: Apidae). J. Econ. Entomol. 97, 752-756 (2004). 
39. Cox-Foster, D. L. et al. A metagenomic survey of microbes in honey bee colony collapse disorder. Science 318, 283-287 (2007).

40. Ahn, J. H. et al. Pyrosequencing analysis of the bacterial communities in the guts of honey bees Apis cerana and Apis mellifera in Korea. J. Microbiol. 50, 735-745 (2012).

41. Engel, P. et al. Standard methods for research on Apis mellifera gut symbionts. J. Apic. Res. 52, 1-24 (2013),

42. Martinson, V. G., Moy, J. \& Moran, N. A. Establishment of characteristic gut bacteria during development of the honeybee worker. Appl. Environ. Microbiol. 78, 2830-2840 (2012).

43. Mohr, K. I. \& Tebbe, C. C. Field study results on the probability and risk of a horizontal gene transfer from transgenic herbicideresistant oilseed rape pollen to gut bacteria of bees. Appl. Environ. Microbiol. 75, 573-582 (2007).

44. Dowd, S. E. et al. Evaluation of the bacterial diversity in the feces of cattle using 16S rDNA bacterial tag-encoded FLX amplicon pyrosequencing (bTEFAP). BMC Microbiol. 8, 125 (2008).

45. Sogin, M. L. et al. Microbial diversity in the deep sea and the underexplored "rare biosphere". Proc. Natl. Acad. Sci. 103, 12115-12120 (2006).

46. Zhou, X. et al. Ultra-deep sequencing enables high-fidelity recovery of biodiversity for bulk arthropod samples without PCR amplification. GigaScience 2, 4 (2013).

47. Martinson, V. G. et al. A simple and distinctive microbiota associated with honey bees and bumble bees. Mol. Ecol. 20, 619-628 (2011).

48. Sabree, Z. L., Hansen, A. K. \& Moran, N. A. Independent studies using deep sequencing resolve the same set of core bacterial species dominating gut communities of honey bees. PLoS One 7, e41250 (2012).

49. Crotti, E. et al. Acetic acid bacteria, newly emerging symbionts of insects. Appl. Environ. Microbiol. 76, 6963-6970 (2010).

50. Ryu, J. H. et al. Innate immune homeostasis by the homeobox gene caudal and commensal-gut mutualism in Drosophila. Science 319, 777-782 (2008).

51. Chouaia, B. et al. Delayed larval development in Anopheles mosquitoes deprived of Asaia bacterial symbionts. BMC Microbiol. 12, 1 (2012).

52. Mitraka, E., Stathopoulos, S., Siden-Kiamos, I., Christophides, G. K. \& Louis, C. Asaia accelerates larval development of Anopheles gambiae. Pathog. Glob. Health 107, 305-311 (2013).

53. Romeis, J. et al. Recommendations for the design of laboratory studies on non-target arthropods for risk assessment of genetically engineered plants. Transgenic Res. 20, 1-22 (2011).

54. Li, Y. H., Romeis, J., Wu, K. M. \& Peng, Y. F. Tier-1 assays for assessing the toxicity of insecticidal proteins produced by genetically engineered plants to non-target arthropods. Insect Science 21, 125-134 (2014).

55. Ramirez-Romero, R., Chaufaux, J. \& Pham-Delègue, M. H. Effects of Cryl Ab protoxin, deltamethrin and imidacloprid on the foraging activity and the learning performances of the honeybee Apis mellifera, a comparative approach. Apidologie 36, 601-611 (2005).

56. Castillo, M. et al. Quantification of total bacteria, enterobacteria and lactobacilli populations in pig digesta by real-time PCR. Vet. Microbiol. 114, 165-170 (2006).

57. Muyzer, G., De Waal, E. C. \& Uitterlinden, A. G. Profiling of complex microbial populations by denaturing gradient gel electrophoresis analysis of polymerase chain reaction-amplified genes coding for 16S rRNA. Appl. Environ. Microbiol. 59, 695-700 (1993).

58. Caporaso, J. G. et al. Global patterns of $16 \mathrm{~S}$ rRNA diversity at a depth of millions of sequences per sample. Proc. Natl. Acad. Sci. 108, 4516-4522 (2011)

59. Magoč, T. \& Salzberg, S. L. FLASH: fast length adjustment of short reads to improve genome assemblies. Bioinformatics 27, 2957-2963 (2011).

60. Caporaso, J. G. et al. QIIME allows analysis of high-throughput community sequencing data. Nat. Methods 7, 335-336 (2010).

61. Edgar, R. C., Haas, B. J., Clemente, J. C., Quince, C. \& Knight, R. UCHIME improves sensitivity and speed of chimera detection. Bioinformatics 27, 2194-2200 (2011).

62. Edgar, R. C. UPARSE: highly accurate OTU sequences from microbial amplicon reads. Nat. Methods 10, 996-998 (2013).

63. Quast, C. et al. The SILVA ribosomal RNA gene database project: improved data processing and web-based tools. Nucleic Acids Res. 41, D590-D596 (2013)

64. Yilmaz, P. et al. The SILVA and "All-species Living Tree Project (LTP)" taxonomic frameworks. Nucleic Acids Res. 42, D643-D648 (2013).

\section{Acknowledgements}

The authors thank Xinzheng Huang for his suggestion during the paper preparation. This research was financially supported by the National Natural Science Foundation of China (No. 31201857), the Central Public-interest Scientific Institution Basal Research Fund (No. 2015001), the Agricultural Science and Technology Innovation Program (CAAS-ASTIP-2015-IAR), the Beijing Natural Science Foundation (No. 6162026) and China Scholarship Council (201503250001).

\section{Author Contributions}

P.D. designed research, H.J., P.D. and L.G. performed experiments, Y.L., Y.W. and Q.D. contributed reagents/ materials/analysis tools, H.J. and P.D. analyzed data, H.J., P.D., C.J., and J.E. wrote the paper. All authors have read and approved the final manuscript.

\section{Additional Information}

Accession codes: Raw sequencing data retrieved in this study have been submitted to the National Center for Biotechnology Information (NCBI) Sequence Reads Archive (SRA) under accession number SRP091743.

Supplementary information accompanies this paper at http://www.nature.com/srep

Competing financial interests: The authors declare no competing financial interests.

How to cite this article: Jia, H.-R. et al. No effect of Bt CrylIe toxin on bacterial diversity in the midgut of the Chinese honey bees, Apis cerana cerana (Hymenoptera, Apidae). Sci. Rep. 7, 41688; doi: 10.1038/srep41688 (2017).

Publisher's note: Springer Nature remains neutral with regard to jurisdictional claims in published maps and institutional affiliations. 
(c) (i) This work is licensed under a Creative Commons Attribution 4.0 International License. The images or other third party material in this article are included in the article's Creative Commons license, unless indicated otherwise in the credit line; if the material is not included under the Creative Commons license, users will need to obtain permission from the license holder to reproduce the material. To view a copy of this license, visit http://creativecommons.org/licenses/by/4.0/

(C) The Author(s) 2017 